\title{
Materials Selection of Optimized Titanium Alloys for Aircraft Applications
}

\author{
Renato Altobelli Antunes $^{a}{ }^{(1)}$, Camilo Augusto Fernandes Salvador ${ }^{b}{ }^{\mathbb{D}}$, Mara Cristina Lopes de Oliveira $^{a}$ * \\ ${ }^{a}$ Centro de Engenharia, Modelagem e Ciências Sociais Aplicadas (CECS), Universidade Federal do \\ ABC (UFABC), 09210-580, Santo André, SP, Brasil \\ ${ }^{b}$ Departamento de Engenharia dos Materiais, Universidade Estadual de Campinas (UNICAMP), \\ 13083-860, Campinas, SP, Brasil
}

Received: October 31, 2017; Accepted: January 18, 2018

\begin{abstract}
The aim of the present work was to explore the correlation between the physical metallurgy of titanium alloys and its main attributes to select optimized materials for structural aircraft applications in the landing gear beam. The Ashby's method was employed as the materials selection strategy to consolidate and evaluate the data collected from the current literature in a comprehensive and consistent analysis. Landing gear beam materials are mainly $\beta$ and near- $\beta$ alloys. Considering the need for high specific strength and fatigue resistance, the best candidate among them was Ti-3.5Al-5Mo-6V-3Cr$2 \mathrm{Sn}-0.5 \mathrm{Fe}$ alloy. Finally, a brief discussion of additional aspects related to alloy design, microstructural features and their influence on the mechanical properties is presented.
\end{abstract}

Keywords: titanium alloys, mechanical properties, materials selection, Ashby's method.

\section{Introduction}

The global market for the aircraft industry presents a strong increasing trend. Recently, the Airbus Company forecast a growing need for new airplanes until 2035, representing an investment of over 5 trillion dollars ${ }^{1}$. In this expanding scenario, several aviation programs put forth requests for lowering fuel consumption, $\mathrm{CO}_{2}$ and $\mathrm{NO}_{\mathrm{x}}$ emissions during aircraft operation ${ }^{2}$, thus, weight reduction is a key issue for aircraft manufacturers. Titanium alloys are used in several aircraft components such as landing gears, engine parts, springs, flap tracks, tubes for pneumatic systems and fuselage parts ${ }^{3-5}$. This widespread applicability derives from an impressive set of favorable attributes such as high strength-to-weight ratio, high oxidation resistance, fracture toughness, corrosion resistance, fatigue strength and creep resistance ${ }^{6-8}$. Titanium alloys can be divided into three different classes of alloys, designated as $\alpha, \alpha+\beta$ and $\beta$ alloys. Characteristics such as creep resistance, weldability, elastic modulus, and toughness are affected by the microstructural features of each class ${ }^{9-11}$.

The physical metallurgy of titanium alloys has been explored to enhance specific properties for a variety of engineering applications. Some of the main properties of titanium alloys for structural aircraft components are fatigue strength, impact strength, Young's modulus and hardness ${ }^{12}$. These properties can be tailored according to the alloy composition and microstructure control that can be achieved by proper heat treatments. Different phases and different morphologies for the same phase can be produced depending on the thermal processing of the titanium alloy. This subject will be further explored in section 2 .

Materials selection methods can be used to guide the development of aircraft titanium alloys with optimal mechanical properties. However, as a consequence of the different classes of titanium alloys, the task of selecting the best candidate for a particular application is challenging diverse properties have to be simultaneously addressed. A variety of materials selection strategies can be found to help the designer in the choice of optimum candidates for an engineering application ${ }^{13}$. Ashby et al. ${ }^{14}$ provided a thorough assessment of materials selection strategies based on quantitative analysis, questionnaire (expertise-capture) and inductive reasoning based on previous experience. Recently, multi-criteria decision making (MCDM) methods have drawn much attention solving engineering problems where multiple attributes must be dealt with simultaneously by the designer ${ }^{15-18}$. Chatterjee et al. ${ }^{19}$ have shown the ability of two MCDM methods, VIKOR and ELECTRE II in successfully identify the best candidates for flywheels and sailing-boat masts. Chakraborty and Chatterjee ${ }^{20}$ employed other MCDM methods (TOPSIS and PROMETHEE) to select materials for cryogenic storage tank materials. However, in spite of the suitability of MCDM methods for selection materials when multiple objectives must be met, Ashby's approach ${ }^{14,21}$ is regarded as a robust methodology to screen and rank the best candidates for an engineering application in a simple and direct manner 22,23 . 
Some authors have assessed different titanium alloys for aircraft applications. Huda and $\mathrm{Edi}^{24}$ reported a review on the materials of structures and engines for supersonic aircrafts. They elaborated a survey of design requirements to guide the materials selection for supersonic aircrafts. The information is very useful, but do not provide a direct assessment of the physical metallurgy aspects of titanium alloys that would allow for the development of optimized alloys for structural applications. Inagaki et al. ${ }^{25}$ provided an overview of the main characteristics of different titanium alloys employed in the aerospace industry. Technical information of the main contemporary aircraft titanium alloys is presented in a direct way, correlating the alloy attributes with its application. However, a materials selection procedure to meet the core design criteria is not presented. Santos et al. ${ }^{26}$ provided a materials selection analysis for the interiors of executive airplanes, giving a deep understanding of the design requirements in such application. Notwithstanding, information about aircraft structural applications of titanium alloys is not provided. In this respect, other authors gave a valuable contribution towards the understanding of the role of titanium alloys in the aircraft industry, exposing their main strengths and weaknesses. Boyer ${ }^{27}$ evaluated the potential applications of $\alpha, \alpha+\beta$ and $\beta$ titanium in the aerospace industry, describing the main properties of several specific alloys. Peters et al. ${ }^{28}$ highlighted applications of titanium alloys in the airframe, engine, helicopters and space components. Similar purpose can be found in the report by Veiga et al. ${ }^{29}$ who stressed out the applications of titanium alloys in the biomedical, automotive and aircraft fields, giving emphasis to the Ti-6Al-4V alloy. Henriques ${ }^{30}$ reviewed the production routes for titanium alloys used in the aerospace industry. More recently, Cotton et al. ${ }^{31}$ gave a deep analysis of the potential applications of $\beta$ alloys in the aircraft industry. Useful information about the microstructure, processing and properties correlation of several beta alloys is provided.

In spite of the high-quality reports available in the literature, there is a lack of papers dedicated to the materials selection of titanium alloys for aircraft applications, exploring the correlation between performance and mechanical metallurgy in a comprehensive way. In the light of this scenario, the aim of the present work was to explore the compromise between materials attributes and mechanical metallurgy to select titanium alloys for structural aircraft applications using Ashby's approach. The paper is divided into two parts. An initial section is devoted to describing the different types of titanium alloys used in the aircraft industry. This section will serve as a basis for the materials selection procedure, giving the reader a few materials science essential concepts. The second part applies the concepts described in the first one as a support to the materials selection analysis for a landing gear beam.

\section{Titanium Alloys}

\subsection{Physical metallurgy aspects}

The allotropic transformation temperature in Ti known as $\beta$-transus is placed at about $882^{\circ} \mathrm{C}$. Alloying elements considered $\alpha$-stabilizers ( $\mathrm{Al}, \mathrm{O}, \mathrm{N}$, etc) tend to increment the $\beta$-transus temperature, stabilizing $\alpha$ phase at higher temperatures. On the other hand, the addition of $\beta$-stabilizers ( $\mathrm{Nb}, \mathrm{Ta}, \mathrm{Mo}, \mathrm{V}, \mathrm{Cu}, \mathrm{Co}, \mathrm{Cr}, \mathrm{Ni})$ may reduce it, allowing $\beta$-phase to form at temperatures lower than $882{ }^{\circ} \mathrm{C}^{32}$.

In Ti alloys, the $\beta / \alpha$ interfaces block the dislocation motion, hence, the mechanical strength of any $\beta+\alpha$ microstructure derive from the size, morphology, and distribution of the $\alpha$ phase $^{33}$. The formation of $\alpha$ from $\beta$ usually starts at the $\beta$-phase grain boundaries, giving rise to many colonies of Widmanstätten $\alpha$ phase laths ${ }^{34}$. In addition to the $\beta \rightarrow \alpha$ transformation, many other solid state transformations can be observed in Ti alloys ${ }^{32}$ as the formation of $\omega$ phase which has deleterious effects on mechanical properties, reducing the alloy toughness ${ }^{35,36}$. Since $\alpha$ phase also has a hexagonal crystal structure, it is stiffer and has lesser slip systems than the $\beta$ phase (bcc), thus, it has a limited conformability ${ }^{37}$. To further improve the mechanical properties of $\mathrm{Ti}$ alloys, Ti-6Al-4V was developed with the combined addition of $\alpha$ $(\mathrm{Al})$ and $\beta(\mathrm{V})$ stabilizers. The duplex microstructure with both $\alpha$ and $\beta$ phases present at the room temperature (RT) allows Ti-6Al-4V to achieve yield strength of approximately $1000 \mathrm{MPa}$.

Despite $\beta$ and metastable- $\beta$ (near- $\beta$ ) titanium alloys have been available since the 1950 's, it was only in the 1980's that Ti-15V-3Cr-3Al-3Sn started to be used in aircraft in significant amounts, mainly due to its superior formability and higher tensile strengths than Ti-6Al-4V $\mathrm{V}^{38}$. Then, alloys such as Ti-10V-2Fe-3Al (Ti-10-2-3), Timetal 21S (Ti-14.7Mo2.7Nb-3Al-0.27Si) and Ti-5V-5Mo-5Al-3Cr (Ti-5553) became the most used ones for structural components in the aerospace industry, as undercarriage parts and landing gear components. Ti-10-2-3 forgings have shown an improved fatigue performance, with fatigue strength of $650 \mathrm{MPa}^{37}$. Due to its wider processing window and high fatigue strength (near $700 \mathrm{MPa}$ ), Ti-5553 has been substituting Ti-10-2-3 in several weight-saving applications ${ }^{39}$. Timetal $21 \mathrm{~S}$ is currently the preferred alloy for high-temperature applications, owing to its superior creep and oxidation resistance.

\subsection{Selected alloys}

In order to support the materials selection process developed in the next section, Table 1 brings a summary of many aircraft titanium alloys' properties at a given microstructure. This information was collected from a thorough and extensive literature review. The density values were obtained by calculating the theoretical density of the 
Table 1. Microstructure and engineering properties of aircraft titanium alloys. Heat treatment details abbreviated*.

\begin{tabular}{|c|c|c|c|c|c|}
\hline Alloy & Structure/Heat treatment & $\begin{array}{l}\text { Fatigue limit } \\
\quad(\mathrm{MPa})\end{array}$ & $\begin{array}{l}\text { Yield strength } \\
\quad(\mathrm{MPa})\end{array}$ & $\begin{array}{l}\text { Density } \\
\left(\mathrm{g} . \mathrm{cm}^{-3}\right)\end{array}$ & Reference \\
\hline Ti-15V-3Cr-3Al-3Sn & $\begin{array}{l}\beta \text { matrix with } \alpha \text { precipitates: } \mathrm{ST} \text { at } 810^{\circ} \mathrm{C} \\
(1 \mathrm{~h}) ; \text { WQ; aging at } 500^{\circ} \mathrm{C}(8 \mathrm{~h}) ; \mathrm{AC}\end{array}$ & ---- & 1179 & 4.667 & {$[4]-\mathrm{a}$} \\
\hline Ti-10V-2Fe-3Al & $\begin{array}{l}\beta \text { matrix with } \alpha \text { precipitates: } \mathrm{ST} \text { at } 850^{\circ} \mathrm{C} \\
(1 \mathrm{~h}) ; \text { WQ; aging at } 500^{\circ} \mathrm{C}(8 \mathrm{~h}) ; \mathrm{AC}\end{array}$ & ---- & 932 & 4.571 & {$[4]-b$} \\
\hline Ti-5V-5Mo-5Al-3Cr & $\begin{array}{l}\beta \text { matrix with } \alpha \text { precipitates: } \mathrm{ST} \text { at } 900^{\circ} \mathrm{C} \\
(1 \mathrm{~h}) \text {; WQ; aging at } 500^{\circ} \mathrm{C}(8 \mathrm{~h}) ; \mathrm{AC}\end{array}$ & ---- & 1107 & 4.566 & {$[4]-\mathrm{c}$} \\
\hline $\begin{array}{l}\text { Ti-15V-3Cr-3Al-3Sn with carbon } \\
\text { and boron addition }\end{array}$ & $\begin{array}{l}\beta \text { matrix with } \alpha \text { precipitates: ST at } 810^{\circ} \mathrm{C} \\
(1 \mathrm{~h}) \text {; WQ; aging at } 500{ }^{\circ} \mathrm{C}(8 \mathrm{~h}) ; \mathrm{AC}\end{array}$ & ---- & 1240 & 4.680 & {$[4]-d$} \\
\hline $\begin{array}{l}\text { Ti-10V-2Fe-3Al with carbon and } \\
\text { boron addition }\end{array}$ & $\begin{array}{l}\beta \text { matrix with } \alpha \text { precipitates: } \mathrm{ST} \text { at } 850^{\circ} \mathrm{C} \\
(1 \mathrm{~h}) \text {; WQ; aging at } 500^{\circ} \mathrm{C}(8 \mathrm{~h}) ; \mathrm{AC}\end{array}$ & ---- & 1385 & 4.552 & {$[4]-\mathrm{e}$} \\
\hline $\begin{array}{l}\text { Ti-5V-5Mo-5 } \mathrm{Al}-3 \mathrm{Cr} \text { with carbon } \\
\text { and boron addition }\end{array}$ & $\begin{array}{l}\beta \text { matrix with } \alpha \text { precipitates: } \mathrm{ST} \text { at } 900{ }^{\circ} \mathrm{C} \\
(1 \mathrm{~h}) \text {; WQ; aging at } 500{ }^{\circ} \mathrm{C}(8 \mathrm{~h}) ; \mathrm{AC}\end{array}$ & ---- & 1463 & 4.579 & {$[4]-\mathrm{f}$} \\
\hline Ti-6Al-4.5Cr-1.5Mn & $\begin{array}{l}\text { Equiaxed } \alpha \text { phase with small needles of } \\
\beta \text { phase: aging at } 120-200^{\circ} \mathrm{C} \text {; aging at } \\
\qquad 750^{\circ} \mathrm{C}(1.5 \mathrm{~h}) ; \mathrm{AC}\end{array}$ & ---- & 1051.5 & 4.429 & {$[10]$} \\
\hline Ti-5Al-5Mo-5V-1Cr-1Fe & $\begin{array}{l}\beta \text { matrix; fine } \alpha \text { platelets: } \mathrm{ST} \text { at } 850{ }^{\circ} \mathrm{C} \\
(2 \mathrm{~h}) ; \mathrm{FC} \text {; aging at } 750{ }^{\circ} \mathrm{C}(2 \mathrm{~h}) ; \mathrm{AC} ; \\
\text { aging at } 500^{\circ} \mathrm{C}(4 \mathrm{~h}) ; \mathrm{AC}\end{array}$ & 880 & 1196 & 4.642 & {$[40]$} \\
\hline Ti-6.5Al-3.3Mo-0.3Si & $\begin{array}{l}\beta \text { matrix with } \alpha \text { colonies: Hot forging at } \\
950^{\circ} \mathrm{C} ; \mathrm{ST} \text { at } 1030^{\circ} \mathrm{C}(0.5 \mathrm{~h}) ; \mathrm{FC}\end{array}$ & ---- & 870 & 4.402 & {$[41]-\mathrm{a}$} \\
\hline Ti-6.5Al-3.3Mo-0.3Si-1.5B & $\begin{array}{c}\beta \text { matrix with } \alpha \text { colonies and TiB } \\
\text { whiskers: Hot forging at } 950{ }^{\circ} \mathrm{C} \text {; ST at } \\
1030^{\circ} \mathrm{C}(0.5 \mathrm{~h}) ; \mathrm{FC}\end{array}$ & ---- & 1125 & 4.349 & {$[41]-b$} \\
\hline Ti-6.5Al-3.3Mo-0.3Si-2B & $\begin{array}{l}\beta \text { matrix with } \alpha \text { colonies and TiB } \\
\text { whiskers: Hot forging at } 950{ }^{\circ} \mathrm{C} ; \mathrm{ST} \text { at } \\
1030^{\circ} \mathrm{C}(0.5 \mathrm{~h}) ; \mathrm{FC}\end{array}$ & ---- & 1020 & 4.332 & {$[41]-\mathrm{c}$} \\
\hline Ti-5Al-5V-5Mo-3Cr- $0.5 \mathrm{Fe}$ & $\begin{array}{l}\beta \text { matrix with } \alpha \text { precipitates and globular } \\
\text { primary } \alpha \text { : ST at } 821^{\circ} \mathrm{C}(3 \mathrm{~h}) ; \mathrm{AC} \\
\text { aging at } 621(6 \mathrm{~h}) ; \mathrm{AC}\end{array}$ & ---- & 1245 & 4.609 & {$[42]$} \\
\hline Ti-5Al-5V-5Mo-3Cr-0.5Fe & $\begin{array}{c}\beta \text { matrix with } \alpha \text { precipitates; ST above } \\
\beta \text { transus, SQ to temperatures near } \\
600^{\circ} \mathrm{C}(10 \mathrm{~h}), \mathrm{FC}\end{array}$ & ---- & 1369 & 4.639 & {$[43]-\mathrm{a}$} \\
\hline Ti-12Nb-5Al-5Mo-3Cr- $0.5 \mathrm{Fe}$ & $\begin{array}{c}\beta \text { matrix with } \alpha \text { precipitates; ST } \\
\text { above } \beta \text { transus, SQ to temperatures } \\
\text { near } 600^{\circ} \mathrm{C}(10 \mathrm{~h}), \mathrm{FC}\end{array}$ & ---- & 1220 & 4.840 & [43]-b \\
\hline Ti-3Al-8V-6Cr-4Zr-4Mo & $\begin{array}{l}\beta \text { matrix with } \alpha \text { precipitates; deep rolling } \\
\text { followed by aging at } 400^{\circ} \mathrm{C}(4 \mathrm{~h})\end{array}$ & 670 & ---- & 4.784 & {$[44]$} \\
\hline Ti-3.5Al-5Mo-6V-3Cr-2Sn-0.5Fe & $\begin{array}{c}\beta \text { matrix with primary } \alpha \text { and fine } \\
\text { secondary } \alpha \text { phases: ST at } 775^{\circ} \mathrm{C}(1 \mathrm{~h}) \\
\text { and } 830^{\circ} \mathrm{C}(0.5 \mathrm{~h}) \text { followed by aging at } \\
440{ }^{\circ} \mathrm{C}(8 \mathrm{~h}) ; \mathrm{AC}\end{array}$ & ---- & 1624 & 4.699 & [45] \\
\hline Ti-5Al-5Mo-5V-3Cr-1Zr & $\begin{array}{l}\beta \text { matrix with primary } \alpha \text { and acicular } \\
\text { secondary } \alpha \text { phases: ST at } 790{ }^{\circ} \mathrm{C}(2 \mathrm{~h}) \\
\text { AC; aging at } 600{ }^{\circ} \mathrm{C}(6 \mathrm{~h}) ; \mathrm{AC}\end{array}$ & 656 & 1248 & 4.610 & {$[46]$} \\
\hline $\mathrm{Ti}-2 \mathrm{Al}-9.2 \mathrm{Mo}-2 \mathrm{Fe}$ & $\begin{array}{l}\beta \text { matrix with nano-scaled } \omega \text { and } \alpha \\
\text { precipitates; ST at } 850{ }^{\circ} \mathrm{C}(1 \mathrm{~h}) \text {; WQ; } \\
\text { aging at } 500^{\circ} \mathrm{C}(2 \mathrm{~h}) \text {; WQ. }\end{array}$ & ---- & 1543 & 4.715 & {$[47]$} \\
\hline Ti-15V-3Sn-3Al-3Cr & $\begin{array}{l}\text { Nanosized } \beta \text { grains with nanoscaled } \alpha \\
\text { precipitates; cold rolling }(80 \% \text { thickness } \\
\text { reduction; three passes); aging at } \\
450{ }^{\circ} \mathrm{C}(4 \mathrm{~h})\end{array}$ & ---- & 1483 & 4.704 & [48] \\
\hline
\end{tabular}

*ST: solution treatment; SQ: step-quenching; WQ: water-quenching; AC: air cooling; FC: furnace cooling. 
alloy based on its chemical composition. It is noteworthy that the vast majority of the references do not report the alloy's fatigue limit, thus revealing a lack of information regarding the fatigue behavior of aircraft titanium alloys in the current literature.

\section{Materials Selection}

\subsection{Fundamentals of Ashby's method}

A detailed description of Ashby's method for materials selection can be found can be found in Ashby, 2004 $4^{14}$ and Ashby, 201021. The procedure is comprised of four different steps: translation, screening, ranking, and documentation. Firstly, in the translation step, the design requirements are defined, identifying the material's function, the constraints or minimum attributes that must be respected so that the material can properly perform its function, the objectives of the selection process, seeking for an attribute that must be maximized or minimized and the variables that the designer is free to choose. Next, the candidates that do not meet the constraints are screened from the selection process. In the third step, the surviving candidates are ranked according to the objectives. Finally, the documentation step can give further insights about the suitability of the candidates after ranking.

The methodology described in the previous paragraph can be applied in a more comprehensive way if the material function is clearly defined. Consequently, in order to give the reader an accurate view of the problem, the materials selection procedure will be applied for the landing gear beam.

\subsection{Materials selection for the landing gear beam}

\section{a) Translation step}

Landing gears are critical components of an aircraft structure, being responsible for supporting the airplane during landing, take-off, parking, and taxiing ${ }^{49}$. The landing gear beam connects the wing to the landing gear, carrying bending loads and acting as a shock absorber ${ }^{50}$. Figure 1 displays part of the landing gear structure of a Boeing 757 airplane, showing the landing gear beam at the upper left. This highly stressed component must be carefully designed to withstand mechanical loads since most aircraft failures are related to landing gears ${ }^{52}$. High specific strength and fatigue resistance are vital properties for the landing gear beam. Titanium alloys meet this profile and, therefore, have dominated this application over the last years ${ }^{53,54}$. Based on this scenario the design requirements for the landing gear beam can be defined as shown in Table 2 . The only constraint is that the landing gear beam must be manufactured using titanium alloys. The objectives were set as to maximize specific strength and fatigue limit simultaneously. Component size and choice of material are the free variables. However, the lack of design data for $\beta$ alloys is considered as a major obstacle for expanding their market share in the aircraft industry ${ }^{31}$. Fatigue properties have been highlighted as important design parameters with insufficient published data in the current literature ${ }^{55,56}$. Hence, we report the yield strength of the alloys in the ordinates. It is an acceptable way of evaluating the data considering the fatigue limit and yield strength of metallic alloys are directly correlated ${ }^{21}$. Nevertheless, one should bear in mind that this approach is an approximation and does not replace or eliminate the need for actual fatigue data. The complexity of titanium alloy microstructures can give rise to different fatigue behaviors for the same particular alloy, depending on its thermomechanical processing history ${ }^{57}$. Moreover, the scattering of high cycle fatigue life for titanium alloys has been reported to be between 2-3 orders of magnitude ${ }^{58}$. Even similar microstructures can give rise to different fatigue properties $^{59}$. As recently pointed by Campanelli et al. ${ }^{60}$, the presence of interstitial hydrogen can be responsible for this behavior. They observed the formation of hydrides in the metastable $\beta$ Ti-5Al-5Mo-5V-3Cr-0.5Fe (Ti-5553) alloy with a hydrogen concentration between 30 and 100 ppmw that led to a variation of up to $100 \mathrm{MPa}$ for the fatigue limit. Furthermore, in addition to the yield strength, the fatigue limit of a material is affected by the type of crack initiation. Microstructures with similar values of yield strength can present different fatigue properties, depending on fatigue crack initiation mode. Microstructures that favor subsurface crack initiation provided higher fatigue limit than those where surface crack initiation dominates. According to Shi et al. ${ }^{40}$, the fatigue limit of the Ti-5Al-5Mo-5V-1Cr-1Fe alloy (Ti 55511) increased for the microstructure with limited volume fraction of coarse $\alpha$-phase due to the high subsurface crack initiation ratio. In spite of this variation, the authors emphasize that the microstructures with high yield strength led to high fatigue limit. In this respect, due to the lack of fatigue data in the current literature, we adopted the yield strength to rank the candidates for the landing gear beam.

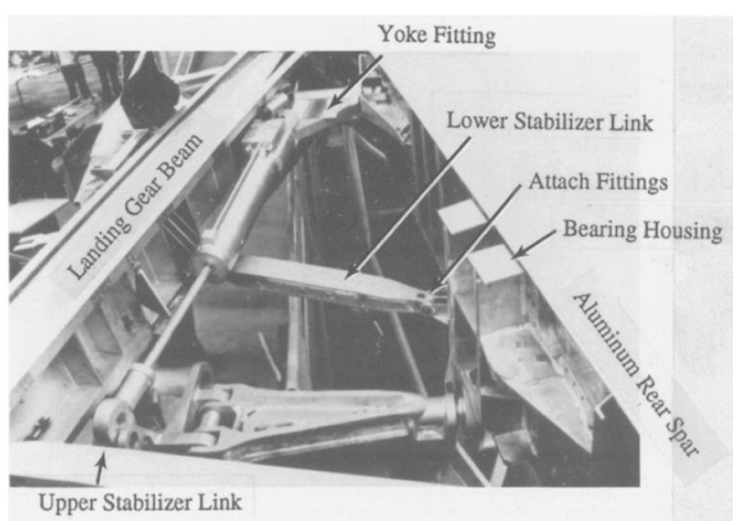

Figure 1. Titanium forging parts in the 757 landing gear structure. The landing gear beam is at the upper left ${ }^{51}$. 
Table 2. Design requirements for the landing gear beam.

\begin{tabular}{ll}
\hline & \multicolumn{1}{c}{ Design requirements } \\
\hline Function & Landing gear beam \\
Constraints & Titanium alloy; section shape specified \\
Objectives & $\begin{array}{l}\text { To maximize specific strength; to maximize } \\
\text { fatigue strength }\end{array}$ \\
Free variables & Component size; choice of material \\
\hline
\end{tabular}

\section{b) Screening, ranking and documentation}

Using the database of the CES Edupack software (version 2009) the chart shown in Fig. 2 was plotted. The two objectives displayed in Table 2 were set as the chart axes. There are 53 possible candidates which represent the whole set of titanium alloys in the software database. The best trade-off between both objectives is met by beta titanium alloys. The ultimate performance is presented by Ti-15-3, Ti-3Al-8V-6Cr-4Zr-4Mo, and Ti-10-2-3.

Following the Ashby methodology, additional information prospected for the selected candidates was considered in order to document the material's choice. Ti-15V-3Cr$3 \mathrm{Sn}-3 \mathrm{Al}$ (Ti15-3) is a prominent $\beta$ alloy with consolidated aircraft applications owing to its high strength-to-weight ratio and cold formability, making it attractive to replace the conventional Ti-6Al-4V in several components ${ }^{61}$. The tensile and fatigue properties are strongly affected by the alloy microstructure. Thus, the performance presented in Fig. 2 can be further optimized by proper heat treatments. Santhosh et al. ${ }^{62}$, for instance, studied the effect of a duplex aging of Ti-15-3 alloy, consisting of a pre-aging for $24 \mathrm{~h}$ at $250{ }^{\circ} \mathrm{C}$ and a final aging for $8 \mathrm{~h}$ at $500{ }^{\circ} \mathrm{C}$. They observed that the duplex heat-treatment provided superior high cycle fatigue properties to the alloy with respect to the conventional one-step aging treatment $\left(10 \mathrm{~h}\right.$ at $\left.500{ }^{\circ} \mathrm{C}\right)$. The improved performance was ascribed to microstructural changes during the duplex treatment, mainly due to the higher number of precipitates per unit volume and a smaller fraction of $\alpha$ phase located at grain boundaries. In this case, grain boundary $\alpha$ nucleation and precipitation free zones are related to the onset of internal fatigue crack initiation ${ }^{63}$.

Ti-3Al-8V-6Cr-4Zr-4Mo alloy (Ti-beta C) has applications in the aircraft industry due to a suitable combination of strength and plasticity ${ }^{64}$. High cycle fatigue and fracture toughness can be tailored depending on prior cold work, followed by proper solution annealing and aging conditions that lead to $\alpha$ precipitation, thus forming a gradient microstructure i.e. a significant hardness increase in near-surface regions without modifying the hardness of the bulk ${ }^{44}$. Ti-10-2-3 was employed in the landing gear structure of Boeing 777 in the 1990's and also by Airbus in the A340-500/600 airplanes ${ }^{16}$. It is mainly used as forged components owing to its excellent ductility ${ }^{65}$. The strength level depends on the thermomechanical processing route by promoting the formation of different microstructures, especially related to the $\alpha$-phase morphology ${ }^{66}$.

The documentation step gives irrefutable evidence for the suitability of the design requirements defined in Table 2 to allow the successful selection of Ti alloys for landing gear

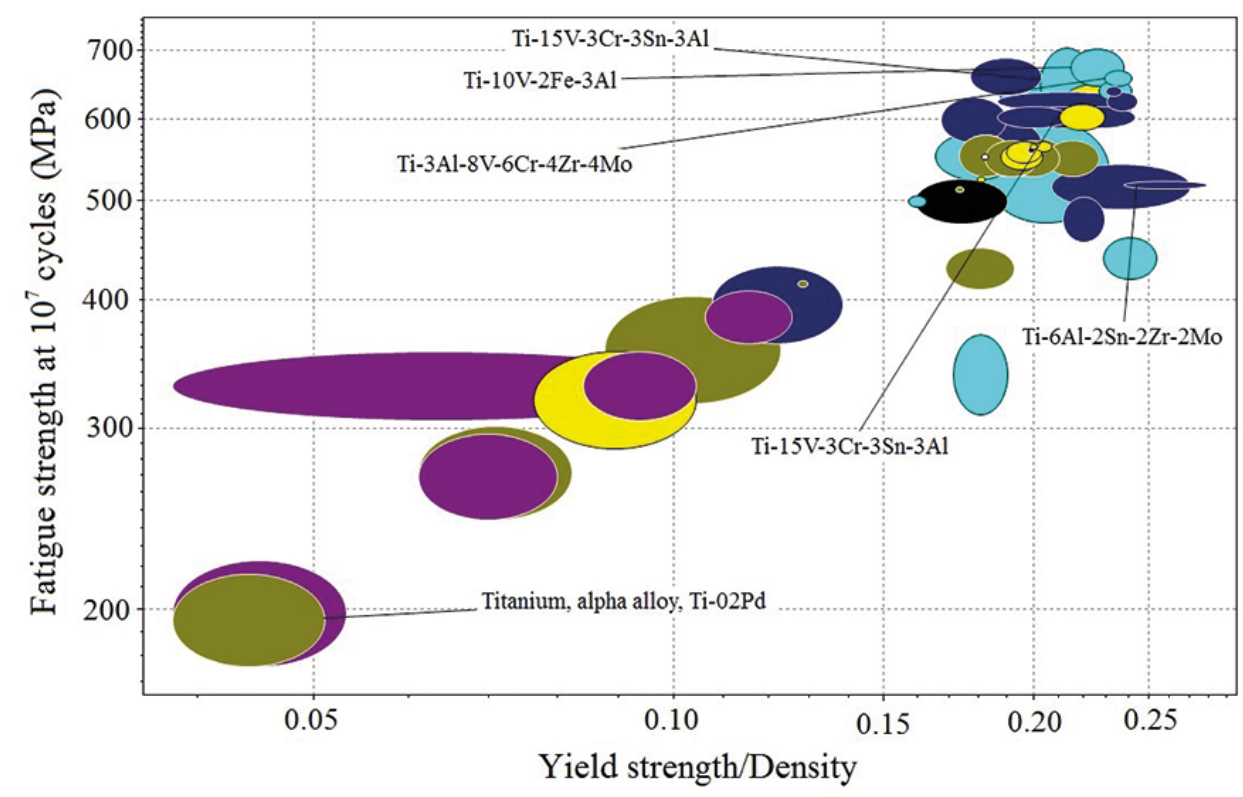

Figure 2. Material property chart for titanium landing gear beam, plotting fatigue strength at $10^{7}$ cycles versus specific strength. Colors: Titanium alloys are in olive, alpha-beta alloys are in navy, beta alloys are in cyan, commercially pure titanium alloys are in purple, near-alpha alloys are in yellow and near-beta alloys are in black. 
beams. In order to expand this scenario, though, further data about 18 newly developed titanium alloys have been collected from the literature and a new chart was plotted (Figure 3), drawing a comparison between the alloys shown in Table 1 with the Ti-15-3, Ti-3Al-8V-6Cr-4Zr-4Mo and Ti-10-2-3 alloys (Fig. 2). This chart does not display the fatigue limit of the alloys since this property was not yet reported for most of the alloys shown in Tab. 1.

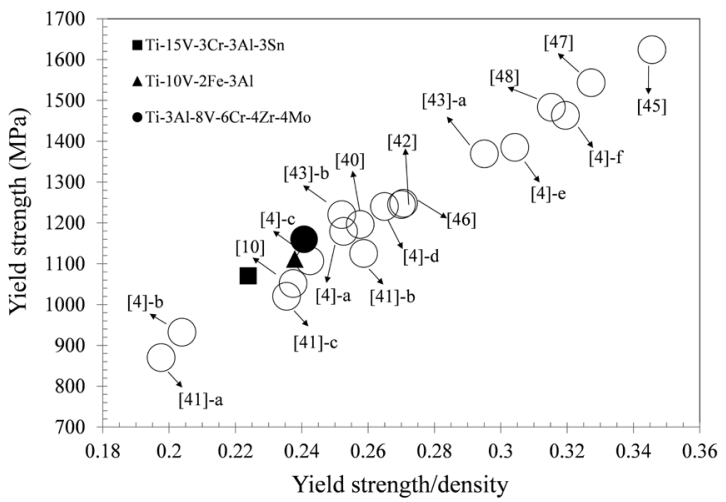

Figure 3. Chart plotting the yield strength versus specific strength of titanium alloys shown in Tab. 1. The data from the CES Edupack 2009 software for the Ti-15V-3Cr-3Sn-3Al, Ti-3Al-8V-6Cr-4Zr-4Mo and Ti-10V-2Fe-3Al alloys (Fig. 2) are also shown for comparison. Each circle represents a titanium alloy at a specific condition. The numbers in square brackets represent the references from which the data were taken, which are also displayed in Tab. 1.

As can be promptly seen in Fig. 3, from the additional 18 alloys whose data are plotted in the chart, there are 13 with better performance than the three standard alloys selected at the first moment. The best performances were for the following materials: [43]-a $<$ [4]-e $<$ [48] $<$ [4]-f $<$ [47] $<$ [45]. The ultimate candidate would be, therefore, Ti-3.5Al$5 \mathrm{Mo}-6 \mathrm{~V}-3 \mathrm{Cr}-2 \mathrm{Sn}-0.5 \mathrm{Fe}^{45}$. It is noteworthy that the third best performance is for Ti-5553 with carbon and boron addition ([4]-f) whereas the standard Ti-5553 alloy ([4]-c) is located far below on the chart. A similar finding can be perceived for Ti-10-2-3 with carbon and boron addition ([4]-e] which is far superior from its standard counterpart ([4]-b]. Hence, small compositional variations can be very effective to shift the base alloy to a new position in the chart, optimizing its performance for the intended application. Controlled carbon and boron additions were successfully employed for Ti-102-3 and Ti-5553 as reported by Banoth et al. ${ }^{4}$. The attention paid to the influence of $\mathrm{B}$ on Ti alloys has been increasing during the last years. Despite the limited solid state solubility of $B$ in both $\beta$ and $\alpha$ phases, its impact on the microstructure and therefore on the mechanical properties of Ti alloys has been reported by several authors. During solidification, small additions of $\mathrm{B}(0.05$ to $0.5 \mathrm{wt} . \%)$ offered an important strategy to control the prior $\beta$ grain size among Ti alloys ${ }^{67,68}$. Also, $\mathrm{B}$ presence leads to a weak $\beta$-phase texture development ${ }^{69}$ which can be beneficial to the mechanical properties. At lower temperatures, stripe-shaped TiB precipitates (referred as whiskers) are commonly formed. They vary from 10100 microns in size and act pinning the grain and phase boundaries, improving the overall mechanical strength. On the other hand, the presence of B-rich particles can result in loss of ductility, depending on their size ${ }^{4}$. According to Seok et al. ${ }^{70}$, the addition of B to Ti-6Al-4V did not alter the $\alpha$ phase volumetric fraction, compared to the base alloy, even though it caused an expressive reduction of the $\alpha-\beta$ colonies size, thus reducing the planar slip length. That was identified as a relevant strengthening mechanism among $\beta+\alpha$ alloys with small $\mathrm{B}$ additions, alongside with the composite effect (i.e. the presence of reinforcing precipitates such as TiB). Analogously, it seems B can increase the critical stress for slip deformation in Ti-based shape memory alloys, enhancing their superelastic behavior ${ }^{71}$. Further studies suggest that the incoherent TiB-B interfaces can assist the $\alpha$-phase precipitation, leading to more fine and dispersed alpha phase precipitates ${ }^{68,72}$, and that the co-addition with $\mathrm{C}$ is useful, reducing $\mathrm{B}$ aggregations on grain boundaries ${ }^{73}$. Additionally, as boron addition affects the alloy microstructure, it is likely to influence the corrosion behavior of structural aircraft titanium alloys. This effect is hardly investigated in the literature. Notwithstanding, there are reports showing that boron addition decreased the corrosion resistance of the biomedical Ti-35Nb-7.2Zr-5.7Ta $\beta$ alloy in a simulated physiological solution ${ }^{74}$. This effect was ascribed to the formation of fine TiB precipitates that lead to a galvanic effect at the interface with the beta matrix. Ravi et al. ${ }^{75}$ have found that pitting corrosion was facilitated when the boron content was above $0.01 \mathrm{wt} . \%$ for the Ti-6Al-4V alloy when exposed to phosphate buffered solution (PBS) at $37^{\circ} \mathrm{C}$. Below this content the resistance to localized corrosion was increased. The authors hypothesized that the beneficial effect of the very low boron additions could be due to the fact that, at such low contents, boron remains in solid solution and do not form precipitates responsible for galvanic effects. Davis et al. ${ }^{76}$, in turn, did not find any evidence of detrimental effects of boron additions to the corrosion resistance of Ti-6Al-4V in Hanks' solution. There is no consensus yet in the literature about the effect of boron addition on the corrosion behavior of titanium alloys but it should not be disregarded when developing new materials for specific applications.

The Ti-15V-3Sn-3Al-3Cr alloy reported by Guo et al. ${ }^{48}$ is also much more attractive than its standard counterpart whose data were taken from the CES Edupack 2009 software. Such optimized behavior is derived from the heat treatments steps to which the alloy was subjected, promoting the formation of nanosized $\beta$ grains and $\alpha$ precipitates.

By analyzing the data displayed in Figs. 2 and 3 it is evident that the performance of well-established aircraft alloys can be optimized by tailoring their chemical composition and microstructure. In this respect, limiting factors for 
achieving the ultimate response to the mechanical loads to which the landing gear beam is subjected depend on proper combinations of alloying elements and favorable microstructural features. The formation of hard nanosized $\alpha$ precipitates within the $\beta$ matrix plays a central role in this scenario. Despite our efforts to rank the materials based on their specific yield strength, the experimental assessment of fatigue properties of recently developed Ti alloys, especially the ones highlighted in this work, seems to be of paramount importance to the aerospace industry.

\section{Conclusions}

In this work, we explored the relationship between the physical metallurgy and performance of structural aircraft titanium alloys, aiming to select the best candidates for the landing gear beam. The materials selection procedure was based on the Ashby method. Two objectives were simultaneously evaluated, to maximize the specific strength and the fatigue strength. Due to the lack of fatigue data for newly developed titanium alloys in the current literature, we used the yield strength as the performance metric instead of the fatigue limit, since these properties are positively correlated. Titanium metastable- $\beta$ alloys provided the best balance between these attributes, being the ultimate performance that of the Ti-3.5Al-5Mo-6V-3Cr-2Sn-0.5Fe alloy. It is important to emphasize, though, that the alloy performance can be optimized by proper microstructural design. The formation of hard nanosized $\alpha$ precipitates within the $\beta$ matrix increases the fatigue strength of $\beta$ alloys. This type of microstructure can be considered an adequate guideline when developing new alloys for the landing gear beam. However, designers should be aware that actual fatigue data of new $\beta$ titanium alloys are still needed to drive the titanium industry in wider markets. The complexity of titanium's physical metallurgy can give rise to specific structural responses depending on the volume fraction and morphologies of $\beta, \alpha$ and $\omega$ phases, as well as the concentration of interstitial elements. In the near future, with new fatigue data, Figure 3 could be remodeled in order to drive an even more accurate selection process.

\section{Acknowledgements}

Mr. Rodney R. Boyer is kindly acknowledged for the permission to reuse the photograph shown in Fig. 1.

\section{References}

1. Airbus. Growing Horizons. Available from: $<$ http://www.airbus. com/aircraft/market/global-market-forecast.html >. Access in: $16 / 06 / 2017$.
2. Uhlmann E, Kersting R, Klein TB, Cruz MF, Borille AV. Additive Manufacturing of Titanium Alloy for Aircraft Components. Procedia CIRP. 2015;35:55-60.

3. Dai J, Zhu J, Chen C, Weng F. High temperature oxidation behavior and research status of modifications on improving high temperature oxidation resistance of titanium alloys and titanium aluminides: A review. Journal of Alloys and Compounds. 2016;685:784-798.

4. Banoth R, Sarkar R, Bhattacharjee A, Nandy TK, Rao GVSN Effect of boron and carbon addition on microstructure and mechanical properties of metastable beta titanium alloys. Materials \& Design. 2015;67:50-63.

5. He DH, Li DS, Li XQ, Jin CH. Optimization on springback reduction in cold stretch forming of titanium-alloy aircraft skin. Transactions of the Nonferrous Metals Society of China. 2010;20(12):2350-2357.

6. Carvalho SM, Baptista CARP, Lima MSF. Fatigue in laser welded titanium tubes intended for use in aircraft pneumatic systems. International Journal of Fatigue. 2016;90:47-56.

7. Shao H, Shan D, Zhao Y, Ge P, Zeng W. Accordance between fracture toughness and strength difference in TC21 titanium alloy with equiaxed microstructure. Materials Science and Engineering: A. 2016;664:10-16.

8. Yao C, Wu D, Ma L, Tan L, Zhou Z, Zhang J. Surface integrity evolution and fatigue evaluation after milling mode, shot-peening and polishing mode for TB6 titanium alloy. Applied Surface Science. 2016;387:1257-1264.

9. Ji Z, Yang H. Microstructural design of two-phase titanium alloys by micro-scale strain distribution. Materials Letters. 2016;184:157-161.

10. Wang HB, Wang SS, Gao PY, Jiang T, Lu XG, Li CH. Microstructure and mechanical properties of a novel near- $\alpha$ titanium alloy Ti6.0A14.5Cr1.5Mn. Materials Science and Engineering: A. 2016;672:170-174.

11. Correa DRN, Kuroda PAB, Grandini CR, Rocha LA, Oliveira FGM, Alves AC, et al. Tribocorrosion behavior of $\beta$-type Ti15Zr-based alloys. Materials Letters. 2016;179:118-121.

12. Singh P, Pungotta H, Kalsi NS. On the characteristics of titanium alloys for the aircraft applications. Materials Today: Proceedings. 2017;4(8):8971-8982.

13. Jahan A, Ismail MY, Sapuan SM, Mustapha F. Material screening and choosing methods - A review. Materials \& Design. 2010;31(2):696-705.

14. Ashby MF, Bréchet YJM, Cebon D, Salvo L. Selection strategies for materials and processes. Materials \& Design. 2004;25(1):51-67.

15. Çalişkan H, Kurşuncu B, Kurbanoglu C, Güven ŞY. Materials selection for the tool holder working under hard milling conditions using different multi criteria decision making methods. Materials \& Design. 2013;45:473-479. 
16. Kumar R, Jagadish, Ray A. Selection of Material for Optimal Design Using Multi-Criteria Decision Making. Procedia Materials Science. 2014;6:590-596.

17. Sen B, Bhattacharjee P, Mandal UK. A comparative study of some prominent multi criteria decision making methods for connecting rod material selection. Perspectives in Science. 2016;8:547-549.

18. Zhang H, Peng Y, Tian G, Wang D, Xie P. Green material selection for sustainability: A hybrid MCDM approach. PLoS One. 2017;12(5): 0177578

19. Chatterjee P, Athawale VM, Chakraborty S. Selection of materials using compromise ranking and outranking methods. Materials \& Design. 2009;30(10):4043-4053.

20. Chakraborty S, Chatterjee P. Selection of materials using multi-criteria decision-making methods with minimum data. Decision Science Letters. 2013;2(3):135-148.

21. Ashby MF. Materials Selection in Mechanical Design. $4^{\text {th }}$ ed. Oxford: Elsevier; 2010.

22. Antunes RA, Oliveira MCL. Materials selection for hot stamped automotive body parts: an application of the Ashby approach based on the strain hardening exponent and stacking fault energy of materials. Materials \& Design. 2014;63:247-256.

23. Bird ET, Bowden AE, Seeley MK, Fullwood DT. Materials selection of flexible open-cell foams in energy absorption application. Materials \& Design. 2018;137:414-421.

24. Huda Z, Edi P. Materials selection in design of structures and engines of supersonic aircrafts: A review. Materials \& Design. $2013 ; 46: 552-560$

25. Inagaki I, Shirai Y, Takechi T, Ariyasu N. Application and Features of Titanium for the Aerospace Industry. Nippon Steel \& Sumitomo Metal Technical Report. 2014;106:22-27.

26. Santos CV, Leiva DR, Costa FR, Gregolin JAR. Materials Selection for Sustainable Executive Aircraft Interior. Materials Research. 2016;19(2):339-352.

27. Boyer RR. An overview on the use of titanium in the aerospace industry. Materials Science and Engineering: A. 1996;213(12):103-114.

28. Peters M, Kumpfert J, Ward CH, Leyens C. Titanium Alloys for Aerospace Applications. Advanced Engineering Materials. 2003;5(6):419-427.

29. Veiga C, Davim JP, Loureiro AJR. Properties and applications of titanium alloys: A brief review. Reviews on Advanced Materials Science. 2012;32:133-148.

30. Henriques VAR. Titanium production for aerospace applications. Journal of Aerospace Technology and Management. 2009;1(1):717.

31. Cotton JD, Briggs RD, Boyer RR, Tamirisakandala S, Russo P, Shchetnikov N, et al. State of the Art in Beta Titanium Alloys for Airframe Applications. JOM. 2015;67(6):1281-1303.

32. Banerjee D, Williams JC. Perspectives on Titanium Science and Technology. Acta Materialia. 2013;61(3):844-879.
33. Fan JK, Li JS, Kou HC, Hua K, Tang B. The interrelationship of fracture toughness and microstructure in a new near $\beta$ titanium alloy Ti-7Mo-3Nb-3Cr-3Al. Materials Characterization. 2014;96:93-99.

34. Bhattacharyya D, Viswanathan GB, Fraser HL. Crystallographic and morphological relationships between $\beta$ phase and the Widmanstätten and allotriomorphic $\alpha$ phase at special $\beta$ grain boundaries in an $\alpha / \beta$ titanium alloy. Acta Materialia. 2007;55(20):6765-6778.

35. Moffat DL, Larbalestier DC. The competition between the alpha and omega phases in aged Ti-Nb alloys. Metallurgical Transactions A. 1988;19(7):1687-1694.

36. Li Y, Yang C, Zhao H, Qu S, Li X, Li Y. New Developments of Ti-Based Alloys for Biomedical Applications. Materials (Basel). 2014;7(3):1709-1800.

37. Boyer RR. Attributes, characteristics, and applications of titanium and its alloys. JOM. 2010;62(5):21-24

38. Boyer RR, Briggs RD. The use of $\beta$ titanium alloys in the aerospace industry. Journal of Materials Engineering and Performance. 2005;14(6):681-685.

39. Campanelli LC, da Silva PSCP, Bolfarini C. High cycle fatigue and fracture behavior of Ti-5Al-5Mo-5V-3Cr alloy with BASCA and double aging treatments. Materials Science and Engineering: A. 2016;658:203-209.

40. Shi X, Zeng W, Xue S, Jia Z. The crack initiation behavior and the fatigue limit of Ti-5Al-5Mo-5V-1Cr-1Fe titanium alloy with basket-weave microstructure. Journal of Alloys and Compounds. 2015;631:340-349.

41. Imayev VM, Gaisin RA, Imayev RM. Effect of boron additions and processing on microstructure and mechanical properties of a titanium alloy Ti-6.5Al-3.3Mo-0.3Si. Materials Science and Engineering: A. 2015;641:71-83.

42. Huang J, Wang Z, Xue K. Cyclic deformation response and micromechanisms of $\mathrm{Ti}$ alloy $\mathrm{Ti}-5 \mathrm{Al}-5 \mathrm{~V}-5 \mathrm{Mo}-3 \mathrm{Cr}-0.5 \mathrm{Fe}$. Materials Science and Engineering: A. 2011;528(29-30):87238732.

43. Opini VC, Salvador CAF, Campo KN, Lopes ESN, Chaves RR, Caram R. $\alpha$ phase precipitation and mechanical properties of Nb-modified Ti-5553 alloy. Materials Science and Engineering: A. 2016;670:112-121.

44. Berg A, Kiese J, Wagner L. Microstructural gradients in Ti-3Al8V-6Cr-4Zr-4Mo for excellent HCF strength and toughness. Materials Science and Engineering: A. 1998;243(1-2):146-149.

45. Du Z, Xiao S, Xu L, Tian J, Kong F, Chen Y. Effect of heat treatment on microstructure and mechanical properties of a new $\beta$ high strength titanium alloy. Materials \& Design. 2014;55:183-190.

46. Huang C, Zhao Y, Xin S, Tan C, Zhou W, Li Q, et al. Effect of microstructure on high cycle fatigue behavior of Ti-5Al-5Mo$5 \mathrm{~V}-3 \mathrm{Cr}-1 \mathrm{Zr}$ titanium alloy. International Journal of Fatigue. 2017;94(Pt 1):30-40. 
47. Li CL, Mi XJ, Ye WJ, Hui SX, Lee DG, Lee YT. Microstructural evolution and age hardening behavior of a new metastable beta Ti-2Al-9.2Mo-2Fe alloy. Materials Science and Engineering. A. 2015;645:225-231.

48. Guo Q, Wang Q, Sun DL, Han XL, Wu GH. Formation of nanostructure and mechanical properties of cold-rolled Ti15V-3Sn-3Al-3Cr alloy. Materials Science and Engineering: A. 2010;527(16-17):4229-4232.

49. Imran M, Shabbir Ahmed RM, Haneef M. FE Analysis for Landing Gear of Test Air Craft. Materials Today: Proceedings. 2015;2(4-5):2170-2178.

50. Brzęczek J, Gruszecki H, Pieróg L, Pietruszka J. Full Scale Fatigue Test of New Undercarriage for Commuter Aircraft. Fatigue of Aircraft Structures. 2012;2012(4):70-75.

51. Boyer RR. Titanium for aerospace: Rationale and applications. Advanced Performance Materials. 1995;2(4):349-368.

52. Xue CJ, Dai JH, Wei T, Liu B, Deng YQ, Ma J. Structural Optimization of a Nose Landing Gear Considering Its Fatigue Life. Journal of Aircraft. 2012;49(1):225-236.

53. Raghunathan SL, Stapleton AM, Dashwood RJ, Jackson M, Dye D. Micromechanics of Ti-10V-2Fe-3Al: In situ synchroton characterisation and modelling. Acta Materialia. 2007;55(20):6861-6872.

54. Srinivasu G, Natraj Y, Bhattacharjee A, Nandy TK, Nageswara Rao GVS. Tensile and fracture toughness of high strength $\beta$ Titanium alloy, Ti-10V-2Fe-3Al, as a function of rolling and solution treatment temperatures. Materials \& Design. 2013;47:323-330.

55. Jha SK, Ravichandran KS. High-cycle fatigue resistance in beta-titanium alloys. JOM. 2000;52(3):30-35.

56. Bettaieb MB, Lenain A, Habraken AM. Static and fatigue characterization of the Ti5553 titanium alloy. Fatigue \& Fracture of Engineering Materials \& Structures. 2013;36(5):401-415.

57. Huang C, Zhao Y, Xin S, Zhou W, Li Q, Zeng W, et al. High cycle fatigue behavior of Ti-5Al-5Mo-5V-3Cr- $1 \mathrm{Zr}$ titanium alloy with bimodal microstructure. Journal of Alloys and Compounds. 2017;695:1966-1975.

58. Yue Y, Dai LY, Zhong H, Zhang XY, Liang SX, Ma MZ, et al. Effect of microstructure on high cycle fatigue behavior of Ti-20Zr-6.5Al-4V alloy. Journal of Alloys and Compounds. 2017;696:663-669.

59. Wu GQ, Shi CL, Sha W, Sha AX, Jiang HR. Effect of microstructure on the fatigue properties of Ti-6Al-4V titanium alloys. Materials \& Design. 2013;46:668-674.

60. Campanelli LC, Silva PSCP, Jorge AM Jr, Bolfarini C. Effect of hydrogen on the fatigue behavior of the near- $\beta$ Ti- $5 \mathrm{Al}-5 \mathrm{Mo}-$ 5V-3Cr alloy. Scripta Materialia. 2017;132:39-43.

61. Hsu HH, Wu YC, Tsay LW. Notch brittleness of Ti-15V3Cr-3Sn-3Al alloys. Materials Science and Engineering: $A$. 2012;545:20-25.

62. Santhosh R, Geetha M, Saxena VK, Rao MN. Effect of duplex aging on microstructure and mechanical behavior of beta titanium alloy Ti-15V-3Cr-3Al-3Sn under unidirectional and cyclic loading conditions. International Journal of Fatigue. 2015;73:88-97.
63. Kim SJ, Hagiwara M, Kawabe Y, Kim SS. Internal crack initiation in high cycle fatigued Ti-15V-3Cr-3Al-3Sn alloys. Materials Science and Engineering: A. 2002;334(1-2):73-78.

64. Łukaszek-Sołek A, Krawczyk J. The analysis of the hot deformation behavior of the Ti-3Al-8V-6Cr-4Zr-4Mo alloy, using processing maps, a map of microstructure and of hardness. Materials \& Design (1980-2015). 2015;65:165-173.

65. Lei L, Huang X, Wang M, Wang L, Qin J, Li H, et al. Effect of hot compressive deformation on the martensite transformation of Ti-10V-2Fe-3Al titanium alloy. Materials Science and Engineering: A. 2011;530:591-601.

66. Quan GZ, Lv WQ, Liang JT, Pu SA, Luo GC, Liu Q. Evaluation of the hot workability corresponding to complex deformation mechanism evolution for Ti-10V-2Fe-3Al alloy in a wide condition range. Journal of Materials Processing and Technology. 2015;221:66-79.

67. Malék J, Hnilica F, Veselý J, Smola B, Březina V, Kolařík K. The effect of boron addition on microstructure and mechanical properties of biomedical Ti35Nb6Ta alloy. Materials Characterization. 2014;96:166-176.

68. Fan Z, MiodownikAP. Microstructural evolution in rapidly solidified Ti-7.5 Mn-0.5 B alloy. Acta Materialia. 1996;44(1):93-110.

69. Roy S, Suwas S, Tamirisakandala S, Miracle DB, Srinivasan R. Development of solidification microstructure in boron-modified alloy Ti-6Al-4V-0.1B. Acta Materialia. 2011;59(14):5494-5510.

70. Seok MY, Zhao Y, Lee JA, Mohamed RM, Al-Harbi LM, Al-Ghamdi MS, et al. On the contributions of different micromechanisms for enhancement in the strength of Ti-6Al-4V upon B addition: A nanomechanical analysis. Materials Science \& Engineering: A. 2016;649:123-127.

71. Al-Zain Y, Kim HY, Miyazaki S. Effect of B addition on the microstructure and superelastic properties of a Ti-26Nb alloy. Materials Science and Engineering: A. 2015;644:85-89.

72. Du ZX, Xiao SL, Wang PX, Xu LJ, Chen YY, Rahoma HKS. Effects of trace $\mathrm{TiB}$ and $\mathrm{TiC}$ on microstructure and tensile properties of $\beta$ titanium alloy. Materials Science and Engineering: A. 2014;596:71-79.

73. Li M, Xiao S, Xiao L, Xu L, Tian J, Chen Y. Effects of carbon and boron addition on microstructure and mechanical properties of TiAl alloys. Journal of Alloys and Compounds. 2017;728:206221.

74. Majumdar P, Singh SB, Chatterjee UK, Chakraborty M. Effect of Heat Treatment and Boron Addition on Corrosion Behavior of Ti-35Nb-7.2Zr-5.7Ta (wt \%) $\beta$-Titanium Alloy in Simulated Body Fluid. Corrosion. 2011;67(8):085001-1.

75. Ravi V, Schissler A, Chantrjaroen W, Beecher C, Razzak A, Urak R, et al. Corrosion behaviour and biocompatibility of boron containing titanium alloys in simulated physiological environments. Corrosion Engineering, Science and Technology. 2012;47(5):383-387.

76. Davis PH, Robles K, Livingston K, Johns S, Ravi VA, Graugnard E, et al. Phase Separation in Ti-6Al-4V Alloys with Boron Additions for Biomedical Applications: Scanning Kelvin Probe Force Microscopy Investigation of Microgalvanic Couples and Corrosion Initiation. JOM. 2017;69(8):1446-1454. 